close to many tropical shores off which the wind blows steadily. For instance, near Cape Guardafui, when the south-west monsoon blows off shore, cold water is found near the land, but when the north-east monsoon blows on shore nothing but warm water can be discovered. The theory is that an off-shore wind blows, or rubs, the sun-heated surface water to leeward, and that the proper level of the sea is maintained by cold water welling up from below. Mr. J. Murray, of the Challenger, has discovered a similar effect in the long, narrow, deep waters of Loch Ness. With a south-west wind the coldest water is at the south-west end of the lake, but when the wind changes to north-east the lowest temperature is found at the north-east extremity.

The remainder of the work is taken up by a description of the currents of the ocean. The theory, of course, is fully given, and we may note that the author uses Ferrel's formula for the deflection of a moving particle to the right, through the influence of the earth's rotation, which has been accepted in every country except England. The long detail of the currents in different oceans of course contains little novelty, but is illustrated by an excellent map in blue and red of the direction and velocity of these well-known cold and hot streams.

Both of these volumes are to a certain extent uncritical compilations, for the results of various experiments and observations are merely recorded, without any comment on the varying quality of the work. We have already commented on the absence of maps; and the instruments used in oceanic research might well have been much more copiously illustrated. Still this work is a most valuable addition to the literature of the subject, and we wish that it could be translated into English.

There is no text-book of the subject in England, beyond School-Board primers, except the work of Maury ; and this, in spite of a fascinating style, is too fanciful, and too much out of date, to be of any use.

Though the volumes now under review can never be popular in the ordinary sense of the word, still they would be invaluable to scientific men and others, who though not specialists wish to study in a compact and available form the present state of knowledge of one of the most interesting branches of modern research.

RALPH ABERCROMBY.

\section{BULLETIN OF THE UNITED STATES FISH COMMISSION.}

Bulletin of the United States Fish Commission. Vol. VI., for 1886. (Washington: Government Printing Office, 1887.)

THE immense number of short articles in this volume are as usual classified in a topical synopsis of the contents. The largest class is that of articles concerning the fisheries, the next in size contains those concerning aquiculture, the next those concerning natural history, and there are two other classes headed U.S. Fish Commission - General, and Miscellaneous. Of the biological articles Mr. John A. Ryder contributes only three, and the reader regrets there are not more from his hand. One is on the early development of the toad-fish, Batrachus tau, whose eggs are described as adherent, being fixed to the under surface of submerged boulders. The young toad-fish have this unique peculiarity, that when the egg-membrane bursts they are not set free but the lower surface of the yolk-sac remains firmly fixed to the adherent portion of the membrane, and this adhesion continues until the yolksac has become almost entirely intra-abdominal. The second of Mr. Ryder's papers is on the cleavage of the blasto-disk in the ovum of Raja erinacea; and the third on the intra-ovarian gestation of the viviparous Sebastes marinus: this last is based upon the examination of a gravid specimen obtained by the Albatross.

The few articles on the reproduction and generative organs of eels are of little value, as the information contained in them is not up to date. One, for instance, is a translation of a paper by Prof. Pavesi, published in I 880 , and therefore of course treating as probabilities propositions concerning the testes which were proved in I 88 I by Otto Hermes.

Among the aquicultural articles there are a great many on the shad-hatching work of the Commission, most of them detailing statistics of the operations of 1886 . In one of these Marshall McDonald announces that for the entire period of the Commission's work up to and including I882, 200,000,000 of young shad were produced, while for I 886 alone the total was $90,000,000$, and this last number was fifteen times as great as the number of adult shad captured for market in one season. In another report by the same writer we find that the cost of production of shad-fry was $\$ 127 \cdot 66$, or about $£ 25$, per million. The exact effect of the artificial production of shad-fry on the supply of the adult fish is not estimated, but in one place we find that the catch in the Potomac was much larger in 1886 than in 1885 ; and in another that in Connecticut pollutions and sewage are diminishing the number of shad in the rivers.

Evidence is given that shad are now fairly abundant on the whole coast of California, apparently from plantings in the River Sacramento, but no regular run of shad seems to have been produced in that river; and we find statistics of plantings in 1886 , in the Columbia and Colorado, from which a better result is expected. But of course the Bulletin is not the place to look for a connected and logical discussion of the operations carried out and their results. The publication contains occasional notes and statistics which are interesting to those who are familiar with the matters to which they belong, and which place on record facts which form materials for a connected study.

Of the very large amount of information comprised under the heading Fisheries, we cannot say more here than that it includes details and statistics not only of American fisheries but of those of all parts of the world.

\section{OUR BOOK SHELF.}

Flour Manufacture: a Treatise on Milling Science and Practice. By Friedrich Kick ; translated by H. H. P. Powles. (London: Crosby Lockwood and Son, 1888.) THE art of flour-milling, which of late years has undergone changes in its method of the most marked character, has at no time been productive of anything like a copious technology ; and, in the attempt to supply this deficiency, it was natural that Mr. Powles should turn his regard towards Austria, where the manufacture of flour had engaged the attention of scientific experts long before the 